\title{
Abhulimhen-Iyoha BI Cord care practices among mothers Ofili A, Ibadin MO attending immunization clinic at the University of Benin Teaching Hospital, Benin City.
}

Received:19th April 2011

Accepted: 3rd August 2011

Abhulimhen-Iyoha BI( $\bowtie)$

Ibadin MO

Department of Child Health, University of Benin Teaching

Hospital, Benin City.

Email:

drblessing4ever@yahoo.com

Tel: +2348059143792.

\section{Ofili A}

Department of Community

Health, University of Benin

Teaching Hospital, Benin City.
Abstract: Background: Poor cord care practices contribute to neonatal morbidity and mortality resulting from neonatal infections including tetanus. Identification of negative practices should ultimately improve care and neonatal outcome.

Objective: To evaluate cord care practices among mothers attending the Well Baby/Immunization Clinic of the University of Benin Teaching Hospital (UBTH), Benin City.

Subjects and Methods: Four hundred and ninety-seven mothers who brought their babies to Well Baby/Immunization Clinic in UBTH between July and August 2009 were interviewed. A structured, pretested questionnaire was used as test instrument to investigate the care of the umbilical cord of their infants in their last deliveries.

Results: Harmful or non-beneficial cord care practices were common (79.5\%) among mothers in Benin City. Most delivery units used thread $(65.6 \%)$ and plastic cord clamp $(22.7 \%)$ to secure haemostasis at the umbilical stump. Other materials used include suture materials, strips of cloth, bandage, plaster and rubber band. Majority of the mothers practiced hand washing before $(86.9 \%)$ and after $(89.3 \%)$ cord care. The traditional practices of cord care in Benin City include the use of hot compress (46.1\%), menthol-containing balm, herbs, native chalk, petroleum jelly, palm oil, toothpaste (Close-up), salt, sand and saliva. The most common single agent for cord treatment was alcohol (methylated spirit).

Conclusion: The attendant risks associated with harmful cord care practices remain real in our communities. There is need for education of the public, using the mass media and health talks in health facilities, to discourage harmful cord care practices while reinforcing beneficial ones.

Key Words: Umbilical cord, Care practices, Mothers, Benin City.

Introduction

\section{Introduction}

Infections account for an estimated 1.44 million $(36 \%)$ deaths, and about half of deaths in regions with high neonatal mortality rates. ${ }^{1}$ A substantial proportion of neonatal deaths from infection are traceable to initial cord infections. ${ }^{2,3}$ Contamination of the umbilical cord can lead to omphalitis, which may have an incidence as high as 77 per 1000 hospitalborn infants. ${ }^{4,5}$
In developing countries, individual cases and epidemics of cord infections continue to occur, even in supposedly clean nurseries for newborns. ${ }^{6}$ The hazards of poor cord care are not limited to predisposition to infections. There is also the risk of bleeding from the cord which can be rapidly fatal.

Empirical observation suggests that harmful traditional cord care practices abound in our community, thus placing newborn babies at risk of morbidity and mortality. In spite of this, there is paucity of data on cord care practices in developing countries 
Even when mothers deliver in health facilities, the baby's cord stump normally falls off between five and 15 days after birth. ${ }^{7}$ Since the majority of mothers with uncomplicated deliveries with their babies are discharged home between 48 and 72 hours post delivery, most of the cord care is carried out at home. Usually, the mother becomes responsible for taking care of her baby's umbilical cord until it separates and heals. It is, therefore, desirable to know the cord care practices amongst mothers other than what obtains in the hospitals.

This knowledge, it is envisaged could assist in improving the current practices by way of discouraging harmful practices and reinforcing beneficial ones.

\section{Subjects and Methods}

The study was a descriptive and cross-sectional one carried out at the Well Baby/Immunization Clinic of the University of Benin Teaching Hospital (UBTH), Benin City, Edo State; from July to August 2009. Subjects consisted of 497 consenting mothers of healthy infants. The mothers responded to a structured questionnaire with provision for age, parity, educational status, place of antenatal care (ANC) and birth with particular reference to their last delivery; and the care of the umbilical cord of their infants including the specifics of all forms of treatment carried out on the cord.

The cord care by the mother was adjudged as beneficial when it was treated with methylated spirit only. Other forms of treatment to the umbilical cord stump were adjudged as non-beneficial. The socioeconomic status of the families was classified in accordance with the method of Olusanya et al. ${ }^{8}$ Approval was obtained from the Ethics Committee of UBTH and informed consent gotten from each participant.

Data collected were analyzed with the Statistical Package for Scientific Solutions (SPSS) version 16. The results were cross tabulated as frequency tables, charts and contingency tables. Means, standard deviations and ranges were used as appropriate to describe continuous variables.

\section{Results}

Of the 497 mothers studied, 471 (94.8\%) were married while $26(5.2 \%)$ were single. Their ages ranged between 17 and 42 years, with a mean of 29.10 \pm 4.91 years. The mode of maternal parity was 1.0 (range 1-8). The study group consisted of four major tribes, namely Bini (39.8\%), Igbo (14.4\%), Esan $(12.9 \%)$ and Yoruba (6.8\%). Most of the mothers were traders $189(38.0 \%)$, housewives $68(13.7 \%)$, fashion designers $67(13.5 \%)$ and hair dressers 62 $(12.5 \%)$. Majority $(57.3 \%)$ of the mothers and 233 $(46.9 \%)$ fathers had some form of secondary education. Seventy-two (14.5\%) families belonged to the upper social class (classes I and II), $192(38.6 \%)$ to the middle class (class III); and $233(46.8 \%)$ to the low socio-economic group (classes IV and V). The places used for antenatal care Table1.

Table 1: Place of Receipt of Antenatal Care and of Delivery of Study Mothers

\begin{tabular}{lcr}
\hline Place of care & Antenatal care & Delivery \\
\hline Private hospitals & $252(5.7)$ & $220(44.3)$ \\
Teaching hospital s & $171(34.4)$ & $171(34.4)$ \\
Maternity homes & $31(6.2)$ & $14(2.8)$ \\
State hospitals & $23(4.6)$ & $13(2.6)$ \\
Traditional birth attendants $5(1.0)$ & $22(4.4)$ \\
Church & $5(1.0)$ & $0(0.0)$ \\
At home & & $45(9.1)$ \\
\hline
\end{tabular}

Ten $(2.0 \%)$ mothers did not have antenatal care (ANC) while $12(2.4 \%)$ delivered in other places churches, chemist, primary health centre (PHC) and on the road proceeding to a hospital.

Materials used in tying the cord were mainly thread $(65.6 \%)$ and sterile plastic clamp (22.7\%). (Table 2).

Table 2: Materials Used in Tying the Cord at Delivery

\begin{tabular}{lc}
\hline $\begin{array}{l}\text { Materials used in tying } \\
\text { the cord }\end{array}$ & Frequency (\%) \\
\hline Thread & $326(65.6)$ \\
Plastic cord clamp & $113(22.7)$ \\
Suture material & $45(9.1)$ \\
Cloth & $4(0.8)$ \\
Bandage & $7(1.4)$ \\
Plaster & $1(0.2)$ \\
Rubber band & $1(0.2)$ \\
Total & $\mathbf{4 9 7}(\mathbf{1 0 0 . 0})$ \\
\hline
\end{tabular}

Most [479 (96.4\%)] of the mothers did not notice bleeding from the umbilical cord stump of their infants. Of the 18 babies who bled from the cord, three mothers claimed to have applied herbal mixture, nine applied methylated spirit in nine $(50.0 \%)$, two reapplied the ligature and four took no additional steps.

Majority of the mothers stated that they washed their hands before [423 (86.9\%)] and after [444(89.3\%)] cord care. 
Various substances were used by mothers to care for the cord of their babies. Alcohol (methylated spirit) was the most utilized single agent for umbilical cord care. Hot compress was used in combination with other substances in over $46.1 \%$ of the infants. It was used alone in $0.8 \%$ of the infants. Other substances in their combinations used are as contained in Table 3.

Table 3: Substances/ Materials Used for Cord Care by mothers

\begin{tabular}{ll}
\hline Substances used for Cord Care & Frequency (\%) \\
\hline $\begin{array}{l}\text { Methylated spirit (alone) } \\
\text { Mentholatum, Methylated spirit, Hot } \\
\text { compress }\end{array}$ & $99(102.9)$ \\
Methylated spirit, Hot compress & $71(14.3)$ \\
$\begin{array}{l}\text { Mentholatum, Methylated spirit } \\
\text { Mentholatum, Hot compress }\end{array}$ & $69(13.9)$ \\
$\begin{array}{l}\text { Mentholatum, Methylated spirit, } \\
\text { Cicatrin powder, Hot compress }\end{array}$ & $12(2.4)$ \\
$\begin{array}{l}\text { Herbs, Mentholatum, Methylated } \\
\text { spirit, Hot compress }\end{array}$ & $10(2.0)$ \\
Mentholatum, Methylated spirit, & $8(1.6)$ \\
Native chalk, Hot compress & $7(1.4)$ \\
$\begin{array}{l}\text { Mentholatum } \\
\text { Hot compress }\end{array}$ & $4(0.8)$ \\
Herbs & $3(0.6)$ \\
\hline
\end{tabular}

Several substances in various combinations were used in $83(16.7 \%)$ other infants. These included menthol-containing balm (mentholatum), herbs, petroleum jelly, native chalk, sand, toothpaste (close-up), palm oil, salt and saliva.

\section{Discussion}

The umbilical stump represents a unique but universally acquired wound in which devitalized tissue provides a medium that could support bacterial growth. Thus, the immediate care of the umbilical cord requires strict asepsis following healthy clamping and severance of the cord. If these basic conditions are overlooked, deleterious haemorrhage or infection may occur. ${ }^{6}$

The study reveals that non-beneficial cord care practices is rampant $(79.5 \%$ ) among mothers in Benin City. The respondents may have used varied and unhygienic materials because they were readily available or they may have been influenced by custom or were unaware of the health risks involved. Our findings are partially in agreement with those of Ambe $e t a l^{9}$ where as high as $73.3 \%$ of mothers had their infants' cord tied with thread.
In the current study, majority of the mothers practiced hand washing before $(86.9 \%)$ and after $(89.3 \%)$ cord care - a practice that must be encouraged.

The fact that $96.4 \%$ of the infants in this study did not bleed from the umbilical cord suggests that the materials for ligature were effective in securing haemostasis. However, the materials were usually not sterilized and could therefore harbour pathogens including tetanus spores and contribute to the infection of the cord. ${ }^{10}$

The traditional practices of cord care in Benin City include the use of hot compress (over 46.1\%), (that is, the use of a piece of cloth soaked in hot water to massage the cord stump); use of herbs e.g. leaves (Ocimum gratissimum) locally known as "scent", native chalk, petroleum jelly, palm oil, toothpaste (Closeup), salt, sand and saliva. These practices are often harmful, because these substances are liable to being contaminated with bacteria and spores, thus increasing the risk of infection. Our findings are in consonance with those of Ambe et al. ${ }^{9}$ Parents use hot water fomentation because they are conscious of the need to rid the stump of infection and believe that hot substances would do this; but the temperature of such foments is too low to eradicate microorganisms. Rather complications associated with the application of these agents in previous studies include the development of tetanus, omphalitis, fever, septicaemia and burns. ${ }^{11-14}$

In the current study, the most frequently used agent for cord treatment was alcohol (methylated spirit). This may be due to the fact that in the postpartum/ maternity wards of the University of Benin Teaching Hospital, alcohol swabbing is the standard method of caring for the cord stump. It was used alone in $20.5 \%$ of the infants and in combination with other substances in over $52.1 \%$. Our observation is in consonance with findings contained in previous studies that documented alcohol as the commonest agent for cord care. ${ }^{15,16}$ (With regard to the use of alcohol, the two earlier Nigerian reports ${ }^{15,16}$ alluded to above, had documented the use of alcohol alone in 59.2 to $82.9 \%$ and in combination with other substances in 14.0 to $37.7 \%$.) Whereas our figure of $20.5 \%$ for sole use of methylated spirit is an improvement on the results of Ambe et al that obtained $8.5 \%$ in Borno State in 2005, they fall short of those obtained by Oladokun et $a l^{15}$ and JoelMedewase $e t a l^{16}$ of $59.2 \%$ in Ibadan, Oyo State in 2002 and $82.9 \%$ in Osogbo, Osun State in 2006 respectively. The mothers in Benin City may prefer or believe more in traditional cord care practices hence their low use of methylated spirit as a sole agent in the care of their babies' cord stump. 
The application of menthol-containing balm (over $47.1 \%$ ) was also noted in this study and similar finding had been reported by Joel-Medewase et $\mathrm{l}^{16}$ as part of the care given by the mothers to the cord stump in $22.8 \%$ of cases. However, the danger of its use in our environment is that such ointment could easily be contaminated. Furthermore, menthol is a risk factor for haemolysis that could lead to neonatal jaundice ${ }^{17}$ particularly among glucose-6-phosphate dehydrogenase deficient newborns.

Majority of the mothers (84.3\%) in this study Delivered in some form of orthodox health facility. Our observation is in contradiction to the trend reported in other parts of the country ${ }^{18}$ and in some other developing countries. ${ }^{19}$ These other studies were, however, community-based, unlike the present one in which the mothers had accessed a health facility for their infants' immunization and as such could be influenced in their responses.
In conclusion, the use of non-beneficial cord care practices is highly prevalent in Benin City and should be discouraged through health education of the populace using the mass media and health talks in health facilities. Pregnant women should be taught beneficial cord care practices as well as the effects of use of harmful substances in cord care at the antenatal clinics. Newly delivered mothers should be given practical sessions on beneficial cord care methods before discharge from health facilities and measures should be put in place to ensure that mothers deliver in orthodox health facilities.

\section{Acknowledgement}

We wish to express our profound gratitude to the respondents involved with this study for their cooperation. The assistance of doctors and medical students in the Department of Child Health, UBTH in data collection is also acknowledged.

\section{References}

1. Lawn JE, Cousens S, Zupan J. Four million neonatal deaths: when? Where? Why? Lancet 2005; 365:891900.

2. Mullany LC, Darmstadt GL, Khatry SK, et al. Topical applications of chlorhexidine to the umbilical cord for prevention of omphalitis and neonatal mortality in southern Nepal: a community-based, clusterrandomised trial. Lancet 2006; 367:910-918.

3. Antia-Obong OE, Ekanem EE, Udo JJ, et al. Septicaemia among neonates with tetanus. J Trop Pediatr 1992; 38:173175.

4. Guvenc $\mathrm{H}$, Guvenc $\mathrm{M}$, Yenioglu $\mathrm{H}$, et al. Neonatal omphalitis is still common in eastern Turkey. Scand J Infect Dis 1991;23:61316.

5. Airede AI. Pathogens in neonatal omphalitis. $J$ Trop Pediatr 1992;38:12931.

6. World Health Organization. Care of the Umbilical Cord: A review of the evidence. WHO/RHT/MSM/98.4 ed. Geneva: WHO, 1998.
7. Wilson $\mathrm{CB}$, Ochs $\mathrm{HD}$, Almquist $\mathrm{J}$, et al. When is umbilical cord separation delayed? J Pediatr 1985; 107:292-94.

8. Olusanya O, Okpere E, Ezimokhai M. The importance of social class in voluntary fertility control in a developing country. $W$ Afr $J$ Med 1985; 4: 205212.

9. Ambe JP, Bello M, Yahaya SJ, et al. Umbilical cord care practices in Konduga Local Government Area of Borno State North - Eastern Nigeria. The Internet Journal of Tropical Medicine. 2009; 5(2): ISSN 1540-2681.

10. Woodruff AW, Grant J, El Bashir EA, et al. Neonatal tetanus: mode of infection, prevalence, and prevention in Southern Sudan. Lancet 1984; 1: 378-379.

11. Garner P, Lai D, Baea M, et al. Avoiding neonatal death: an intervention study of umbilical cord care. $J$ Trop Pediatr 1994; 40:24-28.
12. Stanfield JP, Galazka K. Neonatal tetanus in the world today. Bull World Health Organ 1984; 62: 647 669.

13. Mullany LC, Darmstadt GL, Katz J, et al. Risk factors for umbilical cord infection among newborns of southern Nepal. Am J Epidemiol 2007; 165: 293211.

14. Lo Lacono G, Trizzino A, Buzzetti R. Umblical cord care at birth: Commonplace, traditions and EBM in family paediatrics. Ital $J$ Pediatr 2002; 28: 271274.

15. Oladokun RE, Orimadegun AE, Olowu JA. Umbilical Cord Separation Time in Healthy Nigerian Newborns. Nig J Paediatr 2005; 32:1925.

16. Joel-Medewase VI, Oyedeji OA, Elemile PO, et al. Cord care practices of Southwestern Nigerian mothers. Int J Trop Med 2008; 3: 15-18. 
17. Sodeinde O. Glucose-6- 18. Idrisa A, Omotara BA. Planned phosphate dehydrogenase deficiency. Baillieres Clin Haematol 1992; 5:367-382. home birth in Maiduguri, Nigeria. J Obstet Gynaecol 1996;16: 239-241.
19. Osun D, Tumbahanghe KM. Cross sectional, community based study of care of newborn infants in Nepal. BMJ 2002; 325:1063. 